\title{
$t^{4}$ Report*
}

\section{How are Reproductive Toxicity and Developmental Toxicity Addressed in REACH Dossiers?}

\author{
Costanza Rovida ${ }^{1}$, Fabiola Longo ${ }^{2}$, and Richard R. Rabbit ${ }^{1}$ \\ ${ }^{1}$ Center for Alternatives to Animal Testing (CAAT)-Europe, University of Konstanz, Germany; ${ }^{2}$ Private Consultant, Malnate, \\ Varese, Italy
}

\section{Summary}

The first deadline for REACH registration has passed and registration data for the first set of substances are now public. According to ECHA, 4,599 substances have been registered so far, and the corresponding dossiers of many of them are now partially available in a public database. A sample of 400 records was randomly selected and analyzed with regard to reproductive and developmental toxicity. Most dossiers do not follow the strict requirements in the official guidelines, and some dossiers lack some very basic information. A broad variety of existing data is used, and the read-across opportunity is very much exploited. Surprisingly, a number of in vivo tests have been performed already, apparently for REACH purposes, in spite of the legal requirement to make a public proposal and wait for authorization by ECHA. The number of animals used so far, plus the number of animals that will derive from testing proposals of the first REACH deadline, is very high; it may add up to 1.6 million animals just to accomplish reproductive and developmental toxicity endpoints if the data collected from 400 dossiers are extrapolated to the total number of registered substances. In vitro tests are completely absent, even though there are many tests that may be used to complement either read-across strategies or partially reliable existing data. It is recommended, in the spirit of REACH, to protect human health through an in-depth assessment of the chemicals and simultaneously, to promote the use of in vitro alternatives.

Keywords: REACH, CLP, reproductive toxicity, developmental toxicity, registration dossiers

\author{
Abbreviations \\ CAAT - Center for Alternative to Animal Testing at the Johns \\ Hopkins University, Baltimore, USA \\ CAS number - Chemical Abstracts Service registry numbers \\ assigned by American Chemical Society as unique numerical \\ identifiers for chemical elements, compounds, polymers, \\ biological sequences, mixtures and alloys \\ CLP - Classification Labelling \& Packaging \\ CMR - Carcinogenic, Mutagenic, or toxic to Reproduction \\ CSA - Chemical Safety Assessment \\ CSR - Chemical Safety Report \\ ECHA - European Chemicals Agency, Helsinki, Finland \\ EC number - European Commission number is a seven- \\ digit code that is assigned to chemical substances that are \\ commercially available within the European Union
}

EINECS - European Inventory of Existing Commercial Chemical Substances

ELINCS - European List of Notified Chemical Substances

GHS - Globally Harmonized System

GLP - Good Laboratory Practice

HPV - High Production Volume

IUCLID - International Uniform Chemical Information Database

Non phase-in substances - all substances that have been notified according to Dangerous Substances Directive 67/548/ EEC and to those newly introduced to the market after the implementation of REACH

OECD TG - OECD (Organisation for Economic Co-operation and Development) Test Guideline (www.oecd-ilibrary.org/ environment/oecd-guidelines-for-the-testing-of-chemicals_ chem_guide_pkg-en)

*a report of $\mathrm{t}^{4}$ - the transatlantic think tank for toxicology, a collaboration of the toxicolgically oriented chairs in Baltimore,

Konstanz and Utrecht sponsored by the Doerenkamp-Zbinden Foundation

Received September 24, 2011; accepted in revised form October 27, 2011. 


\author{
Abbreviations (continued) \\ Phase-in substances - all substances that were on the \\ EC market before 18 September 1981 ("existing chemicals") \\ and those previously designated as polymer and no longer \\ considered as such (NLP) \\ (Q)SAR - Quantitative Structure Activity Relationship \\ (computational toxicology, "in silico" method) \\ RAR - Risk Assessment Report \\ REACH - Registration, Evaluation, Authorization and restriction \\ of Chemicals \\ SDS - Safety Data Sheet \\ SIEF - Substance Information Exchange Forum
}

$\mathbf{t}^{4}$ - Transatlantic Think Tank for Toxicology formed between CAAT and the three toxicological chairs for alternatives to animal experiments endowed by the Doerenkamp-Zbinden-Foundation, Switzerland, at University of Konstanz, Germany, University of Utrecht, The Netherlands, and Johns Hopkins University, Baltimore, USA

TSAR - Tracking System for Alternative test methods Review, Validation and Approval in the Context of EU Regulations on Chemicals

TSCA - Toxic Substances Control Act

TCC - Technical Completeness Check

UVCB - Unknown or Variable Composition, Biological Materials

\section{Introduction}

On December 30, 2006, the Regulation on Registration, Evaluation, Authorization and restriction of Chemicals (REACH, 2006) was published in the Official Journal of the European Union. The driving force for the creation of this regulation was the awareness that thousands of chemicals are circulating and used by European citizens despite an enormous lack of information about their (eco)toxicological characteristics. The possible risk of chemicals is a major concern for European citizens: when asked how likely they feel, personally, that environmental chemicals damage their health, Eurobarometers from 2005 and 2010 stably indicated that $18 \%$ considered this "very likely" and 43\% "fairly likely" (Eurobarometer 73.5 from 06/2010 and 64.1 from 09-10/2005).

This Regulation therefore requires that all chemicals that are marketed and/or manufactured in the European Union in quantities above one ton per year must be fully characterized as to the impact they may have on both human health and the environment. This process requires that a long list of endpoints be addressed, mainly through in vivo experiments. The list of tests that must be considered in the dossiers depends on the tonnage band of the manufactured/marketed chemicals and is more demanding for higher quantities, with steps at 1, 10, 100 and 1000 t/a. Above 10 t/a the registration dossier must also contain a Chemical Safety Report (CSR) that is the result of an extensive Chemical Safety Assessment (CSA).

The REACH regulation sets three deadlines to make old chemicals, i.e., those registered as existing chemicals before the deadline of the Dangerous Substances Directive in 1981, comply with the new requirements. Old chemicals are now defined as "phase-in substances" and correspond to substances found in the EINECS database. Those deadlines are:

1. November 30, 2010

- All substances imported/manufactured in quantities above $1000 \mathrm{t} / \mathrm{a}$

- All substances imported/manufactured in quantities above 1 t/a that are classified as CMRs category 1 or 2 according to Directive 67/548
- All substances imported/manufactured in quantities above 100 t/a that are classified as R50/53, i.e. very toxic for the environment according to Directive 67/548

2. May 30, 2013

- All substances marketed/manufactured in quantities above $100 \mathrm{t} / \mathrm{a}$

3. May 30, 2018

- All substances marketed/manufactured in quantities above $1 \mathrm{t} / \mathrm{a}$

These deadlines apply only to phase-in substances that were on the EU market before 1981. Substances that are in the ELINCS database, i.e. new chemicals under the Dangerous Substances Directive, are considered as registered, but only for the tonnage band that was presented at the time of the submission. In addition, all new substances must also be registered without undue delay.

Implementation of REACH included the creation of the European Chemical Agency (ECHA), located in Helsinki, which is responsible for full management of the registration process. To aid in the preparation of registration dossiers, ECHA distributed IUCLID, a software that is offered for free to help submitters collect all necessary information. It should be remembered that the registration dossier of a substance is composed of a broad variety of data, such as the full analytical identification, the lists of all possible uses in the whole life cycle and related exposure scenarios with risk management measures. To give a sense of the complexity of the process, one dossier requires, on average, the compilation of 10,000 fields in IUCLID (ECHA Report, 2011b).

Before REACH was approved, extensive discussions took place regarding the number of animals that the application of the Regulation would require. In fact, several attempts at predicting that number were carried out by the European Commission (Pedersen et al., 2003; van der Jagt et al., 2004) and others (IEH Report, 2001; RPA and Statistics Sweden, 2002; Höfer et al., 2004; Rovida and Hartung, 2009). In order to reduce the burden for testing on vertebrate animals, REACH implemented several options:

1. Even if Regulation 440/2008 provides a list of all official methods, REACH requires that the latest validated method 
shall be always adopted, i.e. any official OECD or EU Test Guideline (TG) can be applied as soon as it is published. The use of such methods becomes compulsory when they replace in vivo tests on vertebrate animals.

2. All existing data on a substance must be gathered and used before performing new tests. The concept of Weight of Evidence is introduced: when more than two independent studies are available and provide the same result, this result can be accepted despite the lack of full reliability of the study, the lack of GLP compliance, or because insufficient data for a full assessment are provided or the data are derived from non-validated methods. Existing data to be considered include historical human data and epidemiological studies.

3. Article 30 of REACH asks for sharing of all data. All potential registrants for a given substance must manage the registration process jointly, forming a SIEF (Substance Information Exchange Forum). This is done to avoid repeating tests in general. In particular, data sharing is mandatory for in vivo tests. This provision is valid also for companies that are not themselves interested in the registration of that substance but that own the data. The concept of "one substance, one registration" is introduced.

4. New tests can be waived when considered either not necessary or not applicable. The waiving option is suggested, for example, when complete lack of exposure is demonstrated or when an endpoint of greater concern has already been confirmed.

5. Similar substances do not require double tests. The data from a similar substance can be used (read-across) or new tests can be performed on one representative substance of a group of similar substances (grouping).

Applicability of those options is not straightforward, and it requires solid scientific argumentation, as they must not compromise human and environmental health due to misleading results. With this aim, a team of experts in different sectors delivered an extensive document: "Guidance on information requirements and chemical safety assessment: endpoint specific requirements," which is now publicly available on the ECHA website (ECHA, 2008) to provide instruction regarding how to apply adaptations for information requirements for each endpoint. Other relevant guidelines are available for download from the ECHA website ${ }^{1}$.

It was clear from the beginning, however, that many new in vivo tests would be required, as most of the substances circulating in the European Union lack very basic information about their (eco) toxicological properties (Hartung, 2010). In particular, reproductive toxicity and developmental toxicity created the highest concern, as these tests are very demanding in terms of animals and costs, and few data were available when REACH was approved (Rovida and Hartung, 2009; Hartung and Rovida, 2009a).

A new Regulation that complements REACH was published in 2008 and entered into force in 2009. Addressing classification, labelling and packaging of substances and mixtures (CLP, 2008), this Regulation aligns previous EU legislation on classification, labelling and packaging of chemicals with the GHS
(Globally Harmonized System of Classification and Labelling of Chemicals). The GHS is a United Nations system to identify hazardous chemicals and to inform users about these hazards through standard pictograms and phrases on the packaging labels, as well as through safety data sheets (SDS).

In addition to the differences in the hazard statements that now begin with " $H$ " instead of the old "R" phrases, a very important revolution is in place: submitters are now fully responsible for the classification and assessment of the chemical substances that they either manufacture or import into the EU. CLP still contains in its Annex I a full list of chemicals with mandatory harmonized classification, but it is explicitly required that whenever a new hazard is known, it must be immediately communicated to downstream users and consumers. In this sense, the list of Annex I can be considered as only a starting point for classification.

After the first deadline of November 30, 2010, ECHA published a database containing data from all submitted dossiers, excluding what was claimed as confidential. On May 6, 2011, this database contained 4,071 entries relating to 3,242 registered substances. Recently, ECHA published a series of reports providing many details about the registration process (ECHA Reports, 2011a-c). These reports are informative but remain very general, as they do not go in depth into the type of data that are presented by submitters. ECHA is planning an extensive review of only $5 \%$ of those dossiers that do not contain testing proposals.

In the present paper, data from 400 submitted dossiers were analyzed to check for compliance with REACH Regulations and published guidelines. The dossiers were randomly selected among full phase-in registered substances, therefore excluding all ELINCS substances and intermediates. For the reasons given above, the study focuses only on reproductive and developmental toxicity.

\section{Reproductive and developmental toxicity: REACH - CLP requirements}

Studies on reproductive and developmental toxicity are required from Annex VIII onwards, i.e. for all substances marketed or manufactured in quantities above 10 t/a. Moving from Annex VIII through $\mathrm{X}$, the required information for reproductive and developmental toxicity becomes more extensive, as explained in Table 1, which gives the relevant text from REACH. It should be noted that the original requirement (Column 2 of 8.7.2 and identical 8.7.3), about considering a $2^{\text {nd }}$ species, was later deleted: "The study shall be initially performed on one species. A decision on the need to perform a study at this tonnage level or the next on a second species should be based on the outcome of the first test and all other relevant data."

The ECHA guidance about all specific endpoints (ECHA, 2008) explains how to adapt the test requirements (adaptation of Column 2 of REACH Regulation and application of the provisions of Annex XI). In particular, it defines OECD TG 421 and 422 as screening tests demanded by Annex VIII and OECD

1 http://guidance.echa.europa.eu 
Tab. 1: REACH and Reproductive Toxicity, text of the Regulation

\begin{tabular}{|l|l}
\hline COLUMN I \\
STANDARD INFORMATION REQUIRED
\end{tabular}$\quad \begin{aligned} & \text { COLUMN } 2 \\
& \text { SPECIFIC RULES FOR ADAPTATION FROM COLUMN } 1\end{aligned}$

Annex VII

No requirements

Annex VIII

\subsection{Reproductive toxicity}

8.7.1. Screening for reproductive/ developmental toxicity, one species (OECD 421 or 422), if there is no evidence from available information on structurally related substances, from (Q)SAR estimates or from in vitro methods that the substance may be a developmental toxicant
8.7.1. This study does not need to be conducted if:

- the substance is known to be a genotoxic carcinogen and appropriate risk management measures are implemented, or

- the substance is known to be a germ cell mutagen and appropriate risk management measures are implemented, or

- relevant human exposure can be excluded in accordance with Annex XI section 3, or

- a pre-natal developmental toxicity study (Annex IX, 8.7.2) or a two-generation reproductive toxicity study (Annex IX, Section 8.7.3) is available.

If a substance is known to have an adverse effect on fertility, meeting the criteria for classification as Repr Cat 1 or 2: R60, and the available data are adequate to support a robust risk assessment, then no further testing for fertility will be necessary. However, testing for developmental toxicity must be considered.

If a substance is known to cause developmental toxicity, meeting the criteria for classification as Repr Cat 1 or 2: R61, and the available data are adequate to support a robust risk assessment, then no further testing for developmental toxicity will be necessary. However, testing for effects on fertility must be considered.

In cases where there are serious concerns about the potential for adverse effects on fertility or development, either a pre-natal developmental toxicity study (Annex IX, Section 8.7.2) or a two-generation reproductive toxicity study (Annex IX, Section 8.7.3) may be proposed by the registrant instead of the screening study.

\section{Annex IX}

\subsection{Reproductive toxicity}

8.7.2. Pre-natal developmental toxicity study, one species, most appropriate route of administration, having regard to the likely route of human exposure (B.31 of the Commission Regulation on test methods as specified in Article 13(3) or OECD 414).
8.7. The studies do not need to be conducted if:

- the substance is known to be a genotoxic carcinogen and appropriate risk management measures are implemented, or

- the substance is known to be a germ cell mutagen and appropriate risk management measures are implemented, or

- the substance is of low toxicological activity (no evidence of toxicity seen in any of the tests available), it can be proven from toxicokinetic data that no systemic absorption occurs via relevant routes of exposure (e.g. plasma/blood concentrations below detection limit using a sensitive method and absence of the substance and of metabolites of the substance in urine, bile or exhaled air) and there is no or no significant human exposure.

If a substance is known to have an adverse effect on fertility, meeting the criteria for classification as Repr Cat 1 or 2: R60, and the available data are adequate to support a robust risk assessment, then no further testing for fertility will be necessary. However, testing for developmental toxicity must be considered.

If a substance is known to cause developmental toxicity, meeting the criteria for classification as Repr Cat 1 or 2: R61, and the available data are adequate to support a robust risk assessment, then no further testing for developmental toxicity will be necessary. However, testing for effects on fertility must be considered.

8.7.2. The study shall be initially performed on one species. A decision on the need to perform a study at this tonnage level or the next on a second species should be based on the outcome of the first test and all other relevant available data. 


\section{COLUMN I STANDARD INFORMATION REQUIRED \\ 8.7.3. Two-generation reproductive toxicity study, one species, male and female, most appropriate route of administration, having regard to the likely route of human exposure, if the 28-day or 90-day study indicates adverse effects on reproductive organs or tissues}

\section{COLUMN 2 SPECIFIC RULES FOR ADAPTATION FROM COLUMN 1}

8.7.3. The study shall be initially performed on one species. A decision on the need to perform a study at this tonnage level or the next on a second species should be based on the outcome of the first test and all other relevant available to date

\begin{tabular}{|c|c|}
\hline \multicolumn{2}{|l|}{ Annex X } \\
\hline \multirow[t]{6}{*}{ 8.7. Reproductive toxicity } & 8.7. The studies need not be conducted if: \\
\hline & $\begin{array}{l}\text { - the substance is known to be a genotoxic carcinogen and appropriate risk management } \\
\text { measures are implemented, or }\end{array}$ \\
\hline & $\begin{array}{l}\text { - the substance is known to be a germ cell mutagen and appropriate risk management } \\
\text { measures are implemented, or }\end{array}$ \\
\hline & $\begin{array}{l}\text { - the substance is of low toxicological activity (no evidence of toxicity seen in any of } \\
\text { the tests available), it can be proven from toxicokinetic data that no systemic absorption } \\
\text { occurs via relevant routes of exposure (e.g. plasma/blood concentrations below } \\
\text { detection limit using a sensitive method and absence of the substance and of } \\
\text { metabolites of the substance in urine, bile or exhaled air) and there is no or no } \\
\text { significant human exposure. }\end{array}$ \\
\hline & $\begin{array}{l}\text { If a substance is known to have an adverse effect on fertility, meeting the criteria for } \\
\text { classification as Repr Cat } 1 \text { or } 2: \text { R60, and the available data are adequate to support } \\
\text { a robust risk assessment, then no further testing for fertility will be necessary. } \\
\text { However, testing for developmental toxicity must be considered. }\end{array}$ \\
\hline & $\begin{array}{l}\text { If a substance is known to cause developmental toxicity, meeting the criteria for } \\
\text { classification as Repr Cat } 1 \text { or } 2 \text { : R61, and the available data are adequate to support a } \\
\text { robust risk assessment, then no further testing for developmental toxicity will be } \\
\text { necessary. However, testing for effects on fertility must be considered. }\end{array}$ \\
\hline \multicolumn{2}{|l|}{$\begin{array}{l}\text { 8.7.2. Developmental toxicity study, one } \\
\text { species, most appropriate route of } \\
\text { administration, having regard to the likely } \\
\text { route of human exposure (OECD 414). }\end{array}$} \\
\hline $\begin{array}{l}\text { 8.7.3. Two-generation reproductive toxicity } \\
\text { study, one species, male and female, } \\
\text { most appropriate route of administration, } \\
\text { having regard to the likely route of human } \\
\text { exposure, unless already provided as } \\
\text { part of Annex IX requirements }\end{array}$ & \\
\hline
\end{tabular}

TG 414 and 416 as a prenatal developmental toxicity study and a two-generation reproductive study, respectively, as required in Annexes IX and X. A 2009 amendment of the Regulation (Regulation 134/2009) clearly states that derived no-effect levels (DNEL) from these screening tests are not sufficient: " $D N E L$ derived from a screening test for reproductive/developmental toxicity shall not be considered appropriate to meet a prenatal developmental toxicity study or a two-generation reproductive toxicity study." This concept is further underlined in three recent ECHA reports (ECHA Reports, 2011a-c). Under certain circumstances, results from repeated dose studies may be accepted, but only to assign a positive classification to the substance, as it is stated that the absence of alerts coming from those studies does not guarantee the absence of reproductive toxic activity. OECD TG 415 (one generation study) and 426 (developmen- tal neurotoxicity) are not considered as standard methods for REACH requirements, even though existing data are accepted. Repeated-dose toxicity studies may also provide indications for considering the need to investigate developmental neurotoxicity endpoints. Interestingly, the ECHA guidance still refers to the second species for OECD 414 but no longer for 416, and thus, at this point, is more demanding than REACH: "At this tonnage level, progression beyond Stage 1 and 2 will trigger a prenataldevelopmental toxicity study (EU B.31, OECD TG 414) and a two-generation reproductive toxicity study (EU B.35, OECD $T G 416)$ in the most relevant species as a standard data requirement. The need for a developmental toxicity study (EU B.31, OECD TG 414) in a second species should be evaluated, following the guidance presented above in Section R.7.6.6.3." So is the suggestion for DNT endpoints. 
In vivo tests required in Annexes VII and VIII are immediately mandatory, while in vivo tests described in Annexes IX and $\mathrm{X}$ must first undergo a public consultation as a result of a testing proposal. However, when substances require longer tests, corresponding shorter tests shall be waived (ECHA Press Release, 2009). This concept is further underscored in an ECHA Fact Sheet that was specific for both repeated dose and reproductive toxicity (ECHA REACH Fact Sheet, 2009). The opportunities for waiving these tests are handled very restrictively in the ECHA guidance: "the reproductive toxicity studies listed as standard information requirements do not need to be conducted if the three following criteria are met:

1. The substance is of low toxicological activity (no evidence of toxicity seen in any of the tests available) and

2. It can be proven from toxicokinetic data that no systemic absorption occurs via relevant routes of exposure (e.g.plasmal blood concentrations below detection limit using a sensitive method and absence of the substance and of metabolites of the substance in urine, bile or exhaled air) and

3. There is no or no significant human exposure."

Implementation of CLP as Regulation (EC) No 1272/2008 in 2008 amended and implemented important aspects of REACH. In IUCLID there is a specific section for CLP, and the summaries of each section contain the proper fields to insert text for explaining classification decisions taken by the submitters. Unfortunately, this important part of IUCLID is not available in the public database, so it is not possible to know how the submitters decided about the classification of substances.

CLP includes three hazard statements for reproductive toxicity:

- H360, Category 1A and 1B: May damage fertility or the unborn child (state specific effect if known; state route of exposure if it is conclusively proven that no other routes of exposure cause the hazard)

- H361, Category 2: Suspected of damaging fertility or the unborn child (state specific effect if known; state route of exposure if it is conclusively proven that no other routes of exposure cause the hazard)

- H362: May cause harm to breast-fed children

The full list of classification options is given in Table 2. These options can be selected through a top-down menu in the cor- responding IUCLID CLP section, where other possibilities are also given:

- "Conclusive, but not enough for classification" when tests demonstrate that the substance has no reproductive toxicity activity.

- "Inconclusive" when test does not allow a decision.

- "Data Lacking" when there are no experimental results and no other scientific evidence about that property.

CLP also describes in detail how decisions about classification for reproductive toxicity should be made and, more precisely, how to translate in vivo tests into a classification and consequent labelling of the substance.

An important difference between the two regulations is relevant to this paper: REACH clearly distinguishes between reproductive toxicity and developmental toxicity, while CLP keeps reproductive toxicity and prenatal developmental toxicity together and splits the toxicity via lactation into a separate section. The result is that the risk for toxicity via lactation is not very well addressed in REACH registration dossiers, as it has no specific fields in the IUCLID software, but the endpoint is included in the developmental toxicity section.

Finally, it must be noted that special rules are adopted in certain circumstances. For example, isolated intermediates that are either used on site or transported must also be registered with exactly the same deadlines. The dossier is much lighter, however, and no information on reproductive/developmental toxicity is required.

\section{ECHA report about "The use of Alternatives to Testing on Animals for the REACH Regulation"}

According to the provision of Article 117(3) of REACH, every three years ECHA is requested to publish a report on the status of implementation and use of non-animal test methods and testing strategies. The first report was published on the ECHA website on June 30, 2011 (ECHA Report, 2011c): “The Use of Alternatives to Testing on Animals for the REACH Regulation." The report, however, reports not only on uses of alternatives to testing but also includes read-across and data sharing, even though

Tab. 2: CLP Hazard statement codes for Reproductive and developmental toxicity

\begin{tabular}{|l|l|}
\hline Hazard Code & Hazard Statement \\
\hline H360F & May damage fertility \\
\hline H360D & May damage the unborn child \\
\hline H361f & Suspected of damaging fertility \\
\hline H361d & Suspected of damaging the unborn child \\
\hline H360FD & May damage fertility. May damage the unborn child \\
\hline H361fd & Suspected of damaging fertility. Suspected of damaging the unborn child \\
\hline H360Fd & May damage fertility. Suspected of damaging the unborn child \\
\hline H360Df & May damage the unborn child. Suspected of damaging fertility \\
\hline
\end{tabular}


they are not alternative methods, thereby raising the number of "alternative methods use" dramatically.

This report was published simultaneously with a general report about the first years of implementation of REACH and CLP (ECHA Report, 2011b). Both documents are very important to give an understanding of what has happened in recent years. According to this report, by the first deadline of November 30, ECHA had received submissions for 4,599 substances, including phase-in and non-phase-in substances but excluding intermediates. In this report, all dossiers are further analyzed to identify the number of new testing proposals, the type of experimental studies that are considered, and all other opportunities taken to avoid new tests. Only submitted tests performed after 2009 are considered as performed for REACH purposes. These criteria are applied to analyze the entries related to all dossiers, i.e. all studies that have been inserted in a dossier. Regarding toxicity to reproduction and developmental toxicity (paragraph 3.2.7 of this report) the analyses is on 3,533 and 4,217 entries, respectively that are all entries submitted (Tab. 3). In fact, requisite number one of REACH is gathering all information related to that substance and this may lead to several entries for one endpoint for one substance. The result is that a dossier often contains more than one entry per endpoint. Thus the relevance of this table is questionable, as it gives a higher weight to studied substances with multiple entries - some chemicals have up to 10 entries of existing data - compared to non-studied substances, which have just one entry for a waiving option or a new testing proposal (Fig. 1 with some further explanation in the section about Materials and Methods). The report does not explicitly state how many substances are included, stating only that it addresses phase-in substances registered in the tonnage band $>1000 \mathrm{t} / \mathrm{a}$. According to the same report, 1,504 phase-in substances are registered at a tonnage band above $1000 \mathrm{t} / \mathrm{a}$. Considering only substances that were registered at the highest tonnage band is also questionable, as the 2010 deadline included not only all substances marketed above $1000 \mathrm{t}$ /a but also all substances marketed above $100 \mathrm{t} / \mathrm{a}$ and classified as toxic for the environment, as well as all substances marketed above $1 \mathrm{t} / \mathrm{a}$ and classified as carcinogenic, mutagenic, and toxic for reproduction (CMR). Excluding these groups of substances of highest concern from the calculation may mean excluding the most problematic substances with regard to testing requirements. The text just states that the percentages presented in Table 3 are unchanged when non-phase-in substances and substances registered in the tonnage band above $100 \mathrm{t} / \mathrm{a}$ are included. The tables in this report are about submitted studies only. Therefore, information on how many dossiers have empty fields is completely missing, and there is no way to analyze whether something should have been done but has not, i.e. whether a registration dossier lacks important studies.

The ECHA report states once more that screening tests for assessing reproductive toxicity are not acceptable for the evaluation of substances marketed at a higher tonnage band. It is clearly stated that OECD TG 414 is required for substances marketed above $100 \mathrm{t} / \mathrm{a}$, and OECD TG 416 is required for substances marketed above 1000 t/a.

Interestingly, these tables do not contain information about in vitro approaches. In the whole report, the in vitro approach is considered only for mutagenicity, skin and eye irritation. This confirms that no in vitro methods are applied in the testing strategies (Rovida, 2010) for more complex endpoints. From this report it is evident that complex animal tests have been waived through read-across and exploitation of existing data but not by employing alternative test methods or computational methods. Also, very few testing proposals for definitive tests on reproductive toxicity have been submitted, as many of the registrants chose to run screening for reproductive toxicity only, despite the fact that this is explicitly considered insufficient.

\section{Materials and methods}

Data used in the present report were collected on the ECHA website, in the special section dedicated to the full database of submitted dossiers ${ }^{2}$; after the update of May 6, 2011, this

2 http://apps.echa.europa.eu/registered/registered-sub.aspx

Tab. 3: Use of different approaches for registration in REACH according to ECHA (compiled data from Fig. 8, 9 in ECHA Report, 2011c)

\begin{tabular}{|l|c|r|r|r|}
\hline Endpoint Study Record (ESR) & \multicolumn{2}{|c|}{ Reproductive toxicity } & \multicolumn{2}{|c|}{ Prenatal developmental toxicity } \\
\hline & ESR & $\%$ ESR & ESR & ESR \\
\hline Experimental Studies (ES) & 1,852 & $52.4 \%$ & 1,783 & $42.3 \%$ \\
\hline Testing Proposal (TP) & 18 & $0.5 \%$ & 151 & $3.6 \%$ \\
\hline Read Across (RA) & 875 & $24.8 \%$ & 1,254 & $29.7 \%$ \\
\hline FO- IUCLID flag to omit the study (Waiving) & 221 & $6.3 \%$ & 460 & $10.9 \%$ \\
\hline Weight of Evidence (WoE) & 389 & $11.0 \%$ & 451 & $10.7 \%$ \\
\hline QSAR studies & 0 & $0 \%$ & 7 & $0.2 \%$ \\
\hline Miscellaneous (MS) & 177 & $5.0 \%$ & 111 & $2.6 \%$ \\
\hline Total & $\mathbf{3 , 5 3 3}$ & $100 \%$ & $\mathbf{4 , 2 1 7}$ & $100 \%$ \\
\hline
\end{tabular}


database contained 4,071 records. A new update was released recently, and the number of records increased to 4,413 (October 19, 2011). However, the present work does not consider the subsequent updates and is entirely based on the May 6 version.

Many records in this database are related to the same substances, as they have the same EC numbers. By removing all multiple entries, the database was reduced to 3,685 records. According to ECHA, 4,599 substances have been registered so far, but it is not clear how to explain the difference of 914 fewer substances in the database. The database should contain data from all publishable dossiers, i.e. dossiers where authorization for publication has been formally received from the submitter. However, there is no further explanation about the procedure that is in place to go from the assignment of a registration number to the publication of the corresponding dossier in the database. We have to assume that the database is representative of the whole set of registered substances, i.e., 4,599.

For the present assessment, we picked randomly 400 different substances from the database from the whole range of EC numbers, only excluding $4 \mathrm{xx}$ - numbers. The $4 \mathrm{xx}$ - numbers are assigned to ELINCS substances that are already considered as registered according to REACH. Dossiers for those substances are not standard and therefore not representative of a full registration dossier. Another category that was excluded is that of intermediates, either isolated on site or transported. Dossiers for intermediates do not require data about reproductive/developmental toxicity. Information about the type of the submitted dossier was retrieved from an Excel File named "list_substances_phasein.xls", which was downloaded from the sector of the ECHA website 3 in the area titled "List of registered substances." This file lists the publishable substances with a flag indicating whether the registration was for a commercial chemical or for an intermediate. The Excel file version used in the present work was dated May 6, 2011. The latest update was released on September 27, 2011 and contains 3,861 substances.

The assessment started by transferring all database records into an Excel worksheet and sorting them by EC number. Afterward, about one out of every 10 entries was selected and checked in the list_substances_phasein.xls file to determine whether it was related to an intermediate or to a full dossier. In the case of an intermediate, it was discarded and another one selected. The next step was to insert the EC number into the database query on the webpage. When multiple records were returned, they were all evaluated to remove partially filled dossiers. Only the most complete one was selected and the corresponding dossier opened. The following data were checked:

$\rightarrow$ Classification and labelling $\rightarrow$ GHS $\rightarrow$ Reproductive Toxicity

$\rightarrow$ Reproductive Toxicity

$\rightarrow$ Toxicity via lactation

$\rightarrow$ Toxicological information $\rightarrow$ Toxicity to reproduction

$\rightarrow$ Toxicity to reproduction

$\rightarrow$ Developmental toxicity

$\rightarrow$ Toxicity to reproduction: other studies (hardly ever present) In case a dossier included different impurity profiles, classification of the purest was selected. Classification only had one entry that was recorded for that selected substance. These possibilities are:

- Data lacking (default value)

- Inconclusive

- Conclusive, but not sufficient for classification

- H360, H361 (Reproductive Toxicity)

- H362 (Toxicity via Lactation)

Afterward, the area on toxicological information was analyzed. In some cases the field about toxicity to reproduction did not exist, and in those cases it was flagged as "void" (Fig. 1). In many cases, more than one study was inserted in both fields, and therefore some rules were applied to set priorities. The entry was considered as "waived" when this was the only proposal, i.e. no other studies were presented. When not void and not waived, all entries were analyzed, and the key study selected for further assessment. When more than one key study was found, the most relevant (when in doubt, the most recent one) was selected. In most cases, both these criteria were met by the key study. However, all entries were checked, even if they were not included in our file. Data inserted in the section: "other studies" were also considered to aid our assessment, even though not transposed to our Excel file. This decision was taken as few studies were presented and most of them were not homogeneous. When a study was selected, the following parameters were considered:

- Reference type: Publication / Study Report

- Purpose Flag: Key study / supporting study / weight of evidence / disregarded study; in addition: Waiving / Study planned / (Q)SAR / in vitro

- Reliability: 1-4, according to the Klimisch score system

- Year when the study was performed (sometimes it was not distinguishable from the date of the publication or report issue)

- Test Guideline, as reported by the submitter

- Species

- Test material: Yes, same as submitted dossier; No, different. The "No" flag triggers the "Read across selection" for the study

- Substance that was used as read across, if that was the case

- Final Result, expressed as LOAEL (Lower Adverse Effect Level)

The same scheme was applied for both reproductive and developmental toxicity.

Besides the selected study, all other entries were checked for the presence of second species, in vitro tests, or (Q)SAR approaches. If one of these possibilities was used, a second study was considered. All data were stored in an Excel worksheet for further assessment. Details on substance identities and final results are not reported.

\section{Results and discussion}

5.1 General considerations on the approach taken Even though the set of 400 substances can be considered as representative, the present approach has some limitations. The selection was totally random, and the only control was to discard substances that were registered as intermediates only. No other controls were in place, so there is no certainty whether, for

\footnotetext{
3 http://apps.echa.europa.eu/registered/registered-sub.aspx
} 


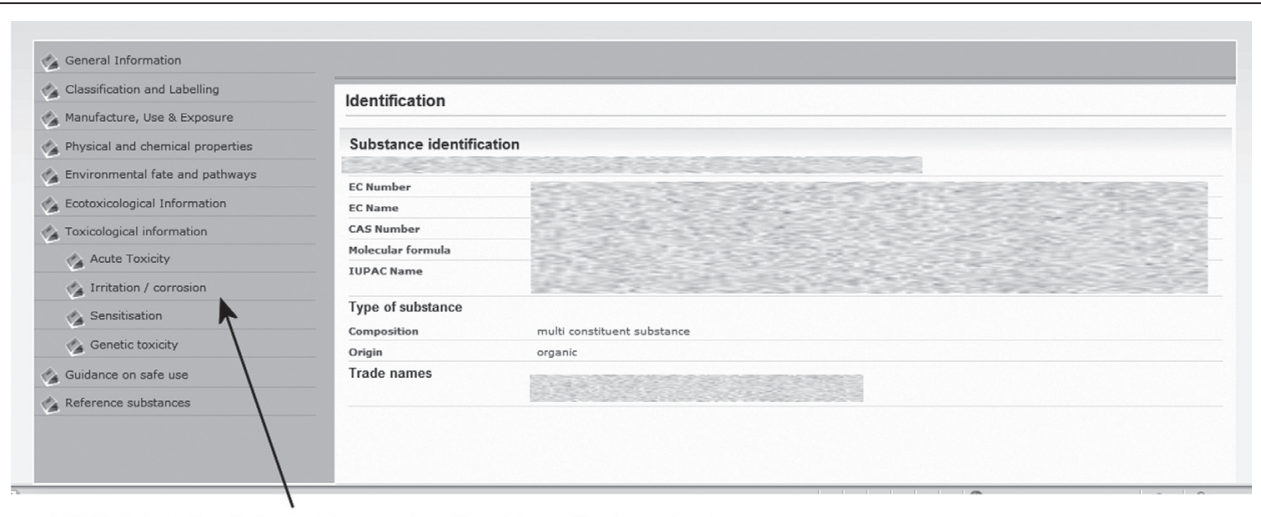

VOID: Endpoint on Reproductive Toxicity is missing

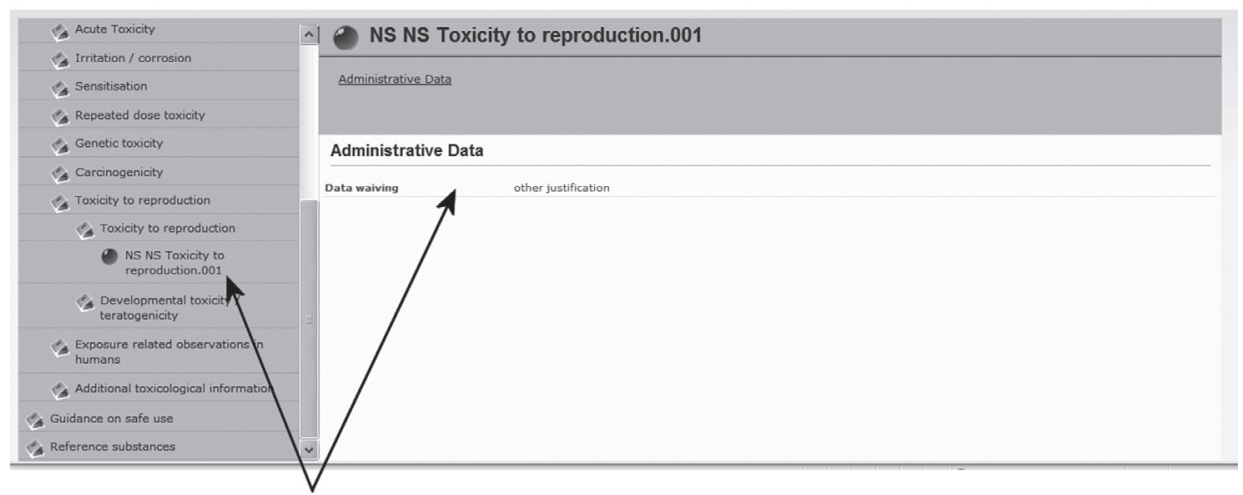

Waived: Test on Toxicity to Reproduction is not performed

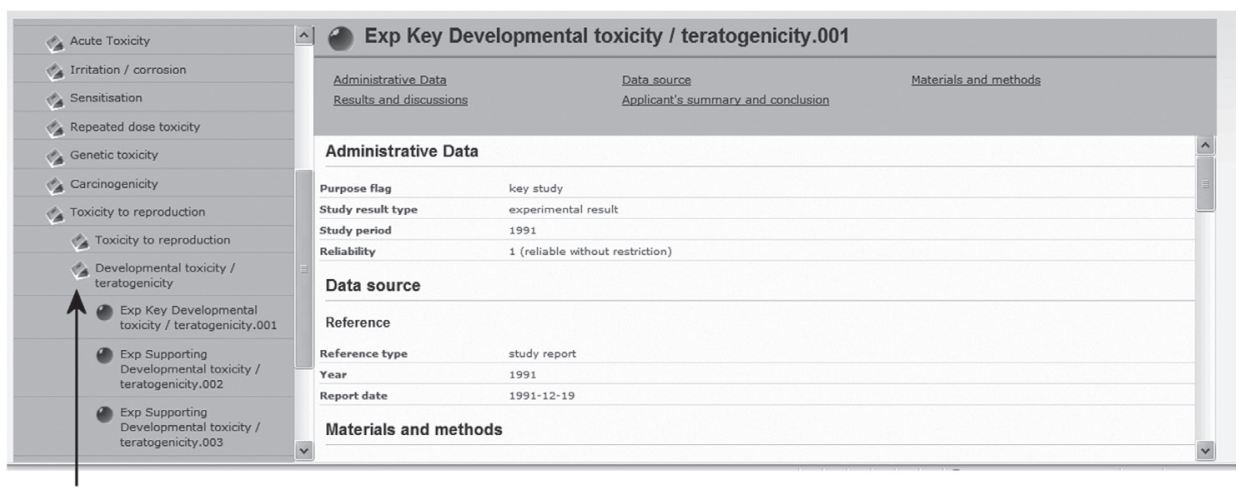

This substance has three entries in the field of Developmental Toxicity/Teratogenicity

Fig. 1: Examples of database windows with void or waived entries and presentation of existing studies

All substance names and references have been blinded.

example, there are enough representatives for CMRs or other classes of chemicals. Moreover, in the public database there is no information about the tonnage band of the dossiers; some early registrations for later deadlines or non-phase-in substances might have been included.

In our analysis, all ELINCS substances (chemicals registered under the Dangerous Substances Directive) had been removed before the set of 400 chemicals was picked. According to
REACH, ELINCS substances are considered registered. A full REACH compliant dossier is required for ELINCS substances for an update in tonnage band and/or in case a new company needs the right to market that substance. As the reason for the presence of an ELINCS substance in the database is not known, all ELINCS substances were disregarded.

Substances registered as intermediates only were excluded, as no data on reproductive toxicity is required for these. In the 
ECHA general report (ECHA Report, 2011b), however, it is stated that $86 \%$ of the substances presented as intermediates appear not to contain sufficient information to demonstrate that the criteria for intermediates are fulfilled. This goes beyond the aim of this paper, however.

Even with no access to the full Chemical Safety Report (CSR), some general considerations regarding the quality of the submitted dossiers are possible. It was evident that there are different interpretations of what IUCLID requires as input. For example, the first recorded input for all dossiers was whether the study was retrieved from a publication or archived as a Company Internal Report. In many dossiers, public studies that are not published in a peer-reviewed journal are regarded as internal reports. In this way, the US National Toxicology Program (NTP) studies, for example, were inserted as either internal or public, making it impossible to use this field for further assessments.

Before entering the study details, some other general information is requested, such as the purpose flag of the study (key study / supporting study / weight of evidence / disregarded study). Obviously, a key study is crucial in the final CSR, and this was always selected when available.

For reliability of the study, the submitter could select among the four different Klimisch scores (Klimisch et al., 1997), i.e.:

1. Reliable without restriction

2. Reliable with restrictions

3. Not reliable

4. Not assignable

The submitter defines the score, and it seems there is a variety of interpretation. Almost all studies performed in the last four to five years were assigned the Klimisch score 1 . However, in the area of reproductive toxicity, 10 studies performed before 1990 were also given a Klimisch score of 1 . Even though the GLP concept was implemented in 1978, it was not generally applied before the early 1990s, so a Klimisch score of 1 is questionable. This is also the impression with regard to the quality of the data found in the dossiers. Notably, there are also two studies ranked Klimisch 2 and dated 1956 and 1952, respectively. The 1952 study is the only one presented for the assessment of reproductive toxicity of the given substance. Apparently the outcome of that study is positive, but the substance is still classified as "conclusive, but not sufficient for classification." Similar conclusions come from the analysis of the section about reproductive toxicity with 29 studies rated Klimisch 1 and performed before 1990.

In this database almost no justification is given when the waiving option is selected, even though this must be present in the corresponding CSR. In some cases it was possible to guess that the waiving option derives from the existence of a Risk Assessment Report (RAR), which represents the official position of the European Commission about a specific chemical or group of chemicals. In the RAR, all studies that led to a decision are presented and commented upon. In those cases the waiving decision is backed by available data. However, the selection of the waiving option in these cases is not correct, and it was not done in the same way for all substances where an RAR is available.

Other general considerations about the submitted dossiers are necessary for animal species selections. Each set of studies per substance was checked for the presence of different species.
Conclusions are that more than $90 \%$ of the studies on reproductive toxicity are performed on rats, with the mouse as the second most common species of choice. In the area of developmental toxicity, about $80 \%$ of studies are on rats, followed by an equal number of studies performed on mice and rabbits, as well as some hamster use. There were only three studies on dogs and one on monkeys, all very old studies. Sheep were used in only one study on reproductive toxicity for a UVCB substance, with no support from additional studies. The same substance has no entry for developmental toxicity, but at least the "inconclusive" flag was selected for CLP. Beyond the anecdotal, it is clear that most of the submitters accepted the results from one species without seeking confirmation of negative results in a second species, as is still suggested in the ECHA guidance for OECD 414 (see above) but deleted from the REACH text. However, the opposite also was found: some studies were on a second species, or such a repeat was suggested when the first one was positive in order to either confirm, or more likely to challenge, the positive outcome or to better understand the mechanism of action. Very often, a positive result is explained as a general toxicity of the substance to the mother and not as a consequence of a real activity of the substance as a reproductive/developmental toxicant. Thus, quite often a positive result is associated with a negative classification of the substance.

The field for epidemiological data was filled in some dossiers, even though it was not considered in the present assessment. In general, however, it appears that epidemiological data are reported but not used for risk characterization, giving a claim of insufficient statistical meaning. We feel that these data are precious and should at least trigger a more in-depth analysis if any alert is raised.

Each analyzed dossier would need further comments. Even though many of them are clearly prepared with care by a team of experts, others lack basic common sense, suggesting that the dossier was prepared in a very superficial manner, despite the REACH request for a detailed chemical risk assessment. Just one example: a substance is classified as "conclusive, but insufficient for classification" for reproductive toxicity. No other classification is assigned, so now that substance can be distributed among consumers with no limitations. In the field for reproductive toxicity, there is the input of a screening test based on OECD TG 421, where the outcome is clearly positive with a reported NOAEL of $60 \mathrm{mg} / \mathrm{kg}$. In addition, there is another study inserted in the field of "Specific investigations" demonstrating an activity of that substance as an endocrine disruptor. According to the submitter, the result from the latter study is "questionable" and no further investigation is proposed.

Another important gap represents developmental neurotoxicity and endocrine disruption that probably represent a concern for some chemicals. However, those endpoints are not explicitly requested by REACH and therefore they are generally not taken into consideration during the preparation of a dossier. In only few cases, those endpoints were mentioned as "other studies", but hardly ever included in the final assessment.

A particularly sore point is that in vitro tests are completely absent. An in vitro test was reported in just three cases and in each case it was performed before 2006 and was already present 
in the public literature, demonstrating that no new alternative tests were done for REACH purposes. This confirms our previous analysis (Rovida, 2010). This is really a missed opportunity, despite the validated embryotoxicity and endocrine disruptor tests and the success of the ReProTect project ${ }^{4}$, an Integrated Project funded by the European Commission that ended with the development of many interesting new tests for reproductive and developmental toxicity. This field definitely deserves more attention in the future, and future submitters should consider in vitro alternatives before doing or planning any in vivo methods, as also suggested by REACH in several Articles.

\subsection{General considerations on the database published on the ECHA website}

On the ECHA website, there is a section dedicated to registered substances ${ }^{5}$. This area includes the link to enter into the full database of submitted dossiers. This database contained 4,071 records after the update of May 6, 2011 and 4,413 records after the October 19, 2011 update. Accepting a disclaimer is mandatory for entering the database: "Information on Registered Substances at http://apps.echa.europa.eu/registered/registeredsub.aspx comes from registration dossiers which have been assigned a registration number. The assignment of a registration number does however not guarantee that the information in the dossier is correct or that the dossier is compliant with REACH. ECHA cannot guarantee the correctness of the information in the database and the REACH Regulation does not permit it to make modifications to the data provided by registrants."

Before inserting a new dossier into this database, ECHA removes some fields that are considered either confidential or not useful for public dissemination. Above all, these include the full CSR text file, which contains the full assessment of the substance and explains all criteria applied, such as justification for read-across and waiving. Another important field that is missing is the endpoint summary, which has a window for "justification for classification." Due to this, it is very difficult to understand why a specific classification is presented despite the discordant results in the studies that are also present in the dossier.

On the same web page, there is also a table that clearly explains the organization of the EC numbers (Tab. 4). The full explanation was already given (Rovida and Hartung, 2009). The only new aspect is the presence of the $7 \mathrm{xx}$ numbers that are related to substances that were not pre-registered.

Furthermore, in the area of registered substances on the ECHA website, it is possible to download an Excel file that contains additional information, such as the type of dossier that has been presented for each substance, i.e. whether it is a full dossier or a dossier for isolated intermediates. This Excel file list includes all substances defined as "Publishable Phase-in Substances." It is not clear which substances are not included in this list, nor how many.

By comparing the records of the database and the substances that are listed in the Excel file (of the same date of update) it was possible to identify all substances that have been registered as intermediates. It was also possible to note that the database contains many double entries, i.e. that more than one dossier was presented for a given chemical. This contradicts the REACH principle "one substance, one registration." ECHA is not sure how this could happen (ECHA Report, 2011b). One substance was found with eight entries and others have seven entries. Probably, each dossier is dedicated to a different use of the substance, but these would need to be combined for the exposure assessment. For the scope of the present assessment, when multiple entries were present, only the one containing the most studies on reproductive toxicity was considered. The full database contains dossiers for 3,685 different substances, as further characterized in Table 4.

Another important difference between the two files refers to the presence in the database of some substances that are missing in the Excel file. Most of these substances are characterized by an EC number of 7xx, having only five representatives in the Excel file and 195 in the database (Tab. 4). In the database, there are also 118 entries with no name, and most of them lack a CAS number as well. Characterization seems very difficult or even impossible.

What is evident from this analysis is that many registered substances are not unique chemical entities, but rather a combination of many chemicals, defined as UVCB (Unknown and Variable Composition, Biological materials). The ECHA Report (2011b) states that this opportunity has been quite extensively applied. In order to try to quantify this contribution, the number of UVCB substances in the ECHA database comes to 1,284 out of 3,484 phase-in substances, i.e. $37 \%$ of the total. The counting was manual, considering all substances as UVCB where the name did not identify a unique chemical entity. A comparison was made with the current situation in the USA: In fact, all US marketed substances, governed by the Toxic Substance Control Act (TSCA), are listed in a file ${ }^{6}$ on the EPA website. In the TSCA list there are 16,550 UVCBs substances out of 66,664 entries, representing $25 \%$ of the total. In this case, counting was easier, as there is a specific flag for identifying UVCBs in the list. The conclusion is that the EU database contains $12 \%$ more UVCBs than expected from the US data over all tonnage bands. It also appears that sometimes substances have been grouped into one dossier. As the full CSR is not accessible, the number of substances that are grouped into one registration is not known. However, this situation is confirmed in ECHA report 2011b: "Companies should ensure that the number of registrations to be made is not artificially reduced by expanding the definition of a substance or merging SIEFs for substances which have entirely different compositions."

The companies' approach is fully understandable. In fact, beyond the number of tests that are required per substance, preparation of each dossier is very demanding. It was estimated that up to 10,000 entries are required for one dossier in IUCLID (ECHA Report, 2011b). Copy and paste options in IUCLID are

\footnotetext{
4 http://www.reprotect.eu

5 http://apps.echa.europa.eu/registered/registered-sub.aspx

6 www.epa.gov/oppt/newchems/index.htm
} 
limited, and most of the entries must be inserted manually. Even if two dossiers are very similar, the preparation of each can take a very long time. Moreover, each submission is accompanied by a fee that must be paid to ECHA, according to Regulation $340 / 2008$ (Tab. 5). Although this fee seems reasonable, together with the workload necessary for each dossier, the process encourages limiting the total number of submissions. The fee set for intermediates is considerably lower. No wonder registrants tried to reduce the number of registrations and also to register a substance as intermediate if possible.

This situation is well described in one of the ECHA reports, which states: "The registration system as set up by REACH may in certain specific circumstances give a competitive disadvantage to diligent companies. According to REACH, the technical completeness check (TCC) shall not include an assessment of the quality or the adequacy of any data or justifications submitted. Therefore in principle this could allow companies to obtain a registration number without making a serious effort to comply with the information requirements." (ECHA report 2011b, page 13).

\subsection{Analysis of submitted studies}

For all 400 analyzed dossiers, the fields about Reproductive Toxicity (section 7.8.1 in IUCLID) and Developmental Toxicity (section 7.8.2 in IUCLID) were considered. General results are presented in Table 6 . In 18 and 20 cases, the corresponding field was simply not present so it was counted as "void." The reason why some dossiers simply do not have that information is difficult to explain: Any submitted IUCLID file is automatically checked for completeness with an informatics tool called TCC (Technical Completeness Check). The TCC checks whether all mandatory fields are completed. As a consequence, the TCC is successful only if sections 7.8.1 or 7.8.2 of IUCLID are properly filled. They may be void only for intermediates and for substances presented in the lowest tonnage band, i.e. below 10 t/a. Or, it may be that the data were presented but were claimed as confidential. The procedure for asking confidentiality is cumbersome, and the fee paid to ECHA quite expensive, so this opportunity is rarely chosen by submitters. A dossier that fails the TCC can still be presented if suitable justification is provided as free text in IUCLID, but this is not an advisable procedure, as it is followed by extensive controls by ECHA.

The number of cases in which the tests are waived is also very high, as it counts 72 and 54 cases, respectively, which represent $17.8 \%$ and $13.3 \%$ of the total. The waiving option is foreseen when the test is technically not possible for any reasons or it is possible to demonstrate that there is no exposure, so that any risks related to reproductive/developmental toxicity is automatically avoided, as explained in the Column 2 of each Annex (Tab. 1).

Read-across is used in $26.8 \%$ and $28 \%$ of dossiers, respectively. The basis is Annex XI of the regulation. It is difficult to understand how the very strict criteria (similar in the ECHA guidance) can actually be applied to so many substances in a data-poor area such as reproductive toxicity testing.

Tab. 4: Definition of EC numbers and number of representatives in the ECHA public database and in the Excel File, both downloaded from the ECHA website with the latest update of May 6, 2011

\begin{tabular}{|c|c|c|c|}
\hline EC Number & Source & $\begin{array}{l}\text { Unique Records } \\
\text { in the Database }\end{array}$ & $\begin{array}{l}\text { Records in } \\
\text { the Excel File }\end{array}$ \\
\hline $2 x x-x x x-x$ & EINECS (European INventory of Existing Commercial chemical Substances) List & 2,538 & 2,588 \\
\hline $3 x x-x x x-x$ & EINECS (European INventory of Existing Commercial chemical Substances) List & 92 & 93 \\
\hline $4 x x-x x x-x$ & ELINCS (European LIst of Notified Chemical Substances) List & 201 & 35 \\
\hline $5 x x-x x x-x$ & NLP (No-Longer Polymers) List & 54 & 40 \\
\hline $6 x x-x x x-x$ & Automatically assigned, e.g. to pre-registrations of substances with a CAS No. & 227 & 168 \\
\hline $7 x x-x x x-x$ & Assigned to substances after inquiries by the ECHA Substance ID Team & 195 & 5 \\
\hline $9 x x-x x x-x$ & $\begin{array}{l}\text { Automatically assigned, e.g. to pre-registrations without a CAS No. or other } \\
\text { numerical identifier }\end{array}$ & 378 & 313 \\
\hline Total & & 3,685 & 3,242 \\
\hline
\end{tabular}

Tab. 5: Fees for registering substances above 1000t/a, according to Regulation 440/2008

\begin{tabular}{|l|c|c|c|c|}
\cline { 2 - 4 } \multicolumn{1}{c|}{} & \multicolumn{2}{c|}{ Full Registration } & \multicolumn{2}{c|}{ Registration of intermediates } \\
\cline { 2 - 5 } \multicolumn{1}{c|}{} & Single submission & Joint submission & Single submission & Joint submission \\
\hline Large Company & $31,000 €$ & $23,250 €$ & $1,600 €$ & $1,200 €$ \\
\hline Medium Enterprise & $21,700 €$ & $16,275 €$ & $1,120 €$ & $840 €$ \\
\hline Small Enterprise & $12,400 €$ & $9,300 €$ & $640 €$ & $480 €$ \\
\hline Micro Enterprise & $3,100 €$ & $2,325 €$ & $160 €$ & $120 €$ \\
\hline
\end{tabular}


Table 6 reports data from the main studies inserted in each dossier, i.e. those that apparently had the highest weight in the final classification. Table 7 further expands these numbers, showing how many of them are associated with other studies for the same purpose. In these tables "QSAR," "Waived," and "Void" are not reported because a dossier is classified as such when no other studies or other contributions were reported. In the analysis, only three in vitro studies were found in the dossiers, but apparently none of them was used as key study for the assessment of the substance. In fact, all the data were published in reviewed journals long before REACH implementation, so clearly the test was not performed for REACH purposes.

The percentage for both waived and void fields is astonishingly high, considering that registered substances should be either HPV or classified as CMRs or environmentally toxic.

As specific rules for adaptation (Tab. 1) include waiving possibilities for carcinogenic and mutagenic substances, the classifications in those areas were checked. Among those waived, six and four carcinogenic substances, respectively, were found; among voids, six carcinogenic substances were found for both, plus two substances classified as H360, which have data in the field for reproductive toxicity and are void in the field of developmental toxicity. Waiving is justified for those substances. Void would be justified if those substances were manufactured/ imported in quantities below $10 \mathrm{t} / \mathrm{a}$. This piece of information is not available, and therefore further considerations are not possible.

Table 6 is mainly based on data inserted in the key study of each dossier. In order to better understand if this approach was correct, the presence of other studies in the same dossier was considered. Results are reported in Table 7 . The only relevant conclusion is that the contribution of read-across probably is underestimated. It is also clear that testing on a second species is not common in the area of reproductive toxicity but is more frequent in developmental toxicity. Further considerations are not possible, as few data have been collected on additional studies.

Another interesting thought concerns the completeness of the submitted dossiers. Definitive numbers cannot be presented

Tab. 6: Category of IUCLID entries for reproductive toxicity and developmental toxicity in the 400 analyzed dossiers

\begin{tabular}{|l|c|c|c|c|}
\cline { 2 - 5 } \multicolumn{1}{c|}{} & \multicolumn{2}{c|}{$\mathbf{7 . 8 . 1}$ Reproductive toxicity } & \multicolumn{2}{c|}{$\mathbf{7 . 8 . 2}$ Developmental/teratogenicity } \\
\hline Existing & 158 & $39.5 \%$ & 169 & $42.3 \%$ \\
\hline Read Across & 107 & $26.8 \%$ & 112 & $28.0 \%$ \\
\hline QSAR/in vitro & 3 & $0.8 \%$ & 2 & $0.5 \%$ \\
\hline Waived & 71 & $17.8 \%$ & 53 & $13.3 \%$ \\
\hline Void & 18 & $4.5 \%$ & 20 & $5.0 \%$ \\
\hline Planned new & 43 & $10.8 \%$ & 44 & $11.0 \%$ \\
\hline
\end{tabular}

Tab. 7: Associations of multiple studies in each registration dossier of the analyzed group of 400 substances

\begin{tabular}{|c|c|c|c|c|}
\hline \multirow[b]{2}{*}{ Existing (total) } & \multicolumn{2}{|c|}{ 7.8.1 Reproductive toxicity } & \multicolumn{2}{|c|}{ 7.8.2 Developmental/teratogenicity } \\
\hline & 158 & $100 \%$ & 169 & $100 \%$ \\
\hline Only one study & 89 & $56 \%$ & 58 & $34 \%$ \\
\hline Associated with studies on same species & 42 & $27 \%$ & 38 & $22 \%$ \\
\hline Associated with studies on different species & 12 & $8 \%$ & 58 & $34 \%$ \\
\hline Associated with studies in read across on same species & 11 & $7 \%$ & 11 & $7 \%$ \\
\hline Associated with studies in read across on different species & 4 & $3 \%$ & 4 & $2 \%$ \\
\hline Read Across (total) & 107 & $100 \%$ & 112 & $100 \%$ \\
\hline Only one study & 64 & $60 \%$ & 47 & $42 \%$ \\
\hline Associated with studies in read across on same species & 27 & $25 \%$ & 38 & $34 \%$ \\
\hline Associated with studies in read across on different species & 16 & $15 \%$ & 27 & $24 \%$ \\
\hline Planned new (total) & 43 & $100 \%$ & 44 & $100 \%$ \\
\hline Only planned study & 19 & $44 \%$ & 34 & $77 \%$ \\
\hline Associated with an existing studies on same substance & 10 & $23 \%$ & 6 & $14 \%$ \\
\hline Associated with studies in read across & 14 & $33 \%$ & 4 & $9 \%$ \\
\hline
\end{tabular}


here, because there is no public information as to the registered tonnage band and to the full CSR of the substance. The high numbers for waiving and voids suggest that missing information was not completely addressed. The broad exploitation of the read-across option adds to this. Moreover, the majority of tests proposed in the area of reproductive toxicity are screening studies only. The categorization that was applied is listed in Table 8. Other applied OECD methods, such as repeated-dose studies, sub-chronic studies, and carcinogenicity studies, were counted as screening methods for the purpose of reproductive toxicity testing. In both fields, the number of studies that are not based on official guidelines is about $40 \%$. Each of these dossiers should be carefully studied to determine whether they are compliant with the requirements.

\subsection{Consistency of presented data with CLP requirements}

Comparison of presented data with CLP requirements is not straightforward, as CLP requires a classification for toxicity on reproduction and prenatal development combined, and it separates the toxicity via lactation. On the other hand, IUCLID has a section for reproductive toxicity only and another one for developmental toxicity, including both prenatal development and toxicity via lactation. Recorded data are presented in Table 9.

Unfortunately, the IUCLID section, which should explain the reasons for classification, is excluded from the public database, so we could just record the data as they are, with no further discussion possible. However, the uncertainty about the classification is evidenced by the number of "Data Lack-

Tab. 8: Categorization of methods that are listed in IUCLID as possible test guideline in the area of Material and methods for Reproductive and Developmental toxicity

IUCLID selection options appear as a drop down menu for selection. Both contain also the item "Other method" with a box to enter free text

\begin{tabular}{|c|c|c|}
\hline \multicolumn{3}{|c|}{ Reproductive Toxicity } \\
\hline & & IUCLID selection options \\
\hline Full & $\rightarrow$ & OECD Guideline 415 (One-Generation Reproduction Toxicity Study) \\
\hline Full & $\rightarrow$ & OECD Guideline 416 (Two-Generation Reproduction Toxicity Study) \\
\hline Screening & $\rightarrow$ & OECD Guideline 421 (Reproduction / Developmental Toxicity Screening Test) \\
\hline Screening & $\rightarrow$ & $\begin{array}{l}\text { OECD Guideline } 422 \text { (Combined Repeated Dose Toxicity Study with the Reproduction / Developmental } \\
\text { Toxicity Screening Test) }\end{array}$ \\
\hline Screening & $\rightarrow$ & OECD Preliminary Reproduction Toxicity Screening Test (Precursor Protocol of GL 421) \\
\hline Screening & $\rightarrow$ & $\begin{array}{l}\text { OECD Combined Repeated Dose and Reproductive / Developmental Toxicity Screening Test } \\
\text { (Precursor Protocol of GL 422) }\end{array}$ \\
\hline Full & $\rightarrow$ & OECD Guideline 426 (Developmental Neurotoxicity Study) \\
\hline Full & $\rightarrow$ & EU Method B.34 (One-Generation Reproduction Toxicity Test) \\
\hline Full & $\rightarrow$ & EU Method B.35 (Two-Generation Reproduction Toxicity Test) \\
\hline Full & $\rightarrow$ & EPA OPP 83-4 (Reproduction and Fertility Effects) \\
\hline Full & $\rightarrow$ & EPA OPP 83-6 (Developmental Neurotoxicity Study) \\
\hline Screening & $\rightarrow$ & EPA OPPTS 870.3500 (Preliminary Developmental Toxicity Screen) \\
\hline Full & $\rightarrow$ & EPA OPPTS 870.3800 (Reproduction and Fertility Effects) \\
\hline Full & $\rightarrow$ & EPA OPPTS 870.6300 (Developmental Neurotoxicity Study) \\
\hline Screening & $\rightarrow$ & EPA OTS 798.4420 (Preliminary Developmental Toxicity Screen) \\
\hline Full & $\rightarrow$ & EPA OTS 798.4700 (Reproduction and Fertility Effects) \\
\hline Screening & $\rightarrow$ & EPA OTS 795.2500 (Developmental Neurotoxicity Screen) \\
\hline Case by case & $\rightarrow$ & Other \\
\hline \multicolumn{3}{|c|}{ Developmental Toxicity } \\
\hline & & IUCLID selection options \\
\hline Full & $\rightarrow$ & OECD Guideline 414 (Prenatal Developmental Toxicity Study) \\
\hline Full & $\rightarrow$ & EU Method B.31 (Prenatal Developmental Toxicity Study) \\
\hline Full & $\rightarrow$ & EPA OPP 83-3 (Prenatal Developmental Toxicity Study) \\
\hline Screening & $\rightarrow$ & EPA OPPTS 870.3600 (Inhalation Developmental Toxicity Screen) \\
\hline Full & $\rightarrow$ & EPA OPPTS 870.3700 (Prenatal Developmental Toxicity Study) \\
\hline Screening & $\rightarrow$ & EPA OTS 798.4350 (Inhalation Developmental Toxicity Screen) \\
\hline Full & $\rightarrow$ & EPA OTS 798.4900 (Prenatal Developmental Toxicity Study) \\
\hline Case by case & $\rightarrow$ & Other: \\
\hline
\end{tabular}


ing" entries found in the dossiers. For substances that are registered at the highest tonnage band, this is difficult to accept. Analysis of reproductive toxicity can be skipped only when the substance is already classified as carcinogenic. About $10 \%$ of the substances that claimed the waiving options for reproductive and developmental toxicity are classified as carcinogenic. The value is higher for voids, as there are five substances that are classified $\mathrm{H} 350$, plus three others that indicate only reproductive or developmental toxicity. The only possible explanation is that those substances are marketed in quantities below $10 \mathrm{t} / \mathrm{a}$.

In order to understand better what is happening, each category was further characterized by checking the entries in the corresponding IUCLID section (Tab.10). The data presented for toxicity via lactation can be misleading, as there is a confusion of classification via lactation with the generic developmental toxicity. Table 10 shows discrepancies, as there are many flags for "Data Lacking" while some results are inserted in the corresponding field. On the other hand, the no-classification label is assigned to substances for which the dossier claims the waiving options or the request to perform new in vivo tests. Both cases should be associated with either "Data Lacking" or "Inconclusive." Only few waivings are suggested for substances that have a full RAR and therefore already justify a classification decision. Apparently, the "Inconclusive" option should be selected most often, but the opposite is the case.

\subsection{New tests performed for REACH purposes and new test proposals}

One of the most interesting aspects of the present analysis concerns the type of recent animal studies that have been submitted. Table 11 lists all the studies performed after 2006. REACH was published on December 30,2006, so the type and number of tests performed in 2006 can be considered as a control, i.e. what occurred before REACH was published. The situation for the year 2007 is borderline, as it is possible that some tests were planned and initiated the year before, when REACH was still not in place. The effect of REACH can be expected from 2008 onwards, and the increasing trend confirms this assumption (Fig. 2). It is immediately evident that the number of studies is increasing, starting from 2008. This is easily explained, as planning and performing a new reproductive/developmental toxicity study requires about a year. REACH was published on December 30, 2006. The first SIEFs were formed in 2007, and 2008 is the right time to reap the first results. Of course, the highest number is for 2010 , the year of the first deadline.

The REACH regulation clearly states that substances that are marketed/manufactured in quantities above $100 \mathrm{t} / \mathrm{a}$ require a full reproductive/developmental study, while a simple screening is sufficient when the limit is $10 \mathrm{t} / \mathrm{a}$. Moreover, full studies can be performed only after proper authorization from ECHA, which must first check whether this is really necessary, a process that includes public consultation. Despite this, 10 new OECD TG 416 studies and 14 new OECD TG 414 studies were performed

Tab. 9: Summary of CLP selections in the 400 analyzed dossiers

\begin{tabular}{|l|c|c|c|c|}
\hline CLP & \multicolumn{2}{|c|}{ Repro/Prenatal Development } & \multicolumn{2}{c|}{ Via Lactation } \\
\hline Non classified & 283 & $71 \%$ & 13 & $53 \%$ \\
\hline Data Lacking & 67 & $17 \%$ & 3 & $46 \%$ \\
\hline Inconclusive & 4 & $1 \%$ & & $0.75 \%$ \\
\hline H360 & 26 & $7 \%$ & & $0 \%$ \\
\hline H361 & 20 & $5 \%$ & 1 & $0 \%$ \\
\hline H362 & & $0 \%$ & $0.25 \%$ \\
\hline
\end{tabular}

Tab. 10: Comparison of CLP selection and submitted studies for the 400 analyzed dossiers

\begin{tabular}{|c|c|c|c|c|c|c|c|}
\hline & CLP & Void & Waived & With Data & Planned & QSAR & Total \\
\hline \multirow[t]{4}{*}{ Toxicity to reproduction } & Data Lacking & 11 & 26 & 18 & 12 & & 67 \\
\hline & Inconclusive & & & 1 & 3 & & 4 \\
\hline & Non classified & 4 & 40 & 208 & 28 & 3 & 283 \\
\hline & Classified & 3 & 5 & 38 & & & 46 \\
\hline \multirow[t]{4}{*}{ Toxicity via lactation } & Data Lacking & 16 & 40 & 107 & 17 & 3 & 183 \\
\hline & Inconclusive & & & 1 & 2 & & 3 \\
\hline & Non classified & 2 & 31 & 156 & 24 & & 213 \\
\hline & Classified & & & 1 & & & 1 \\
\hline
\end{tabular}




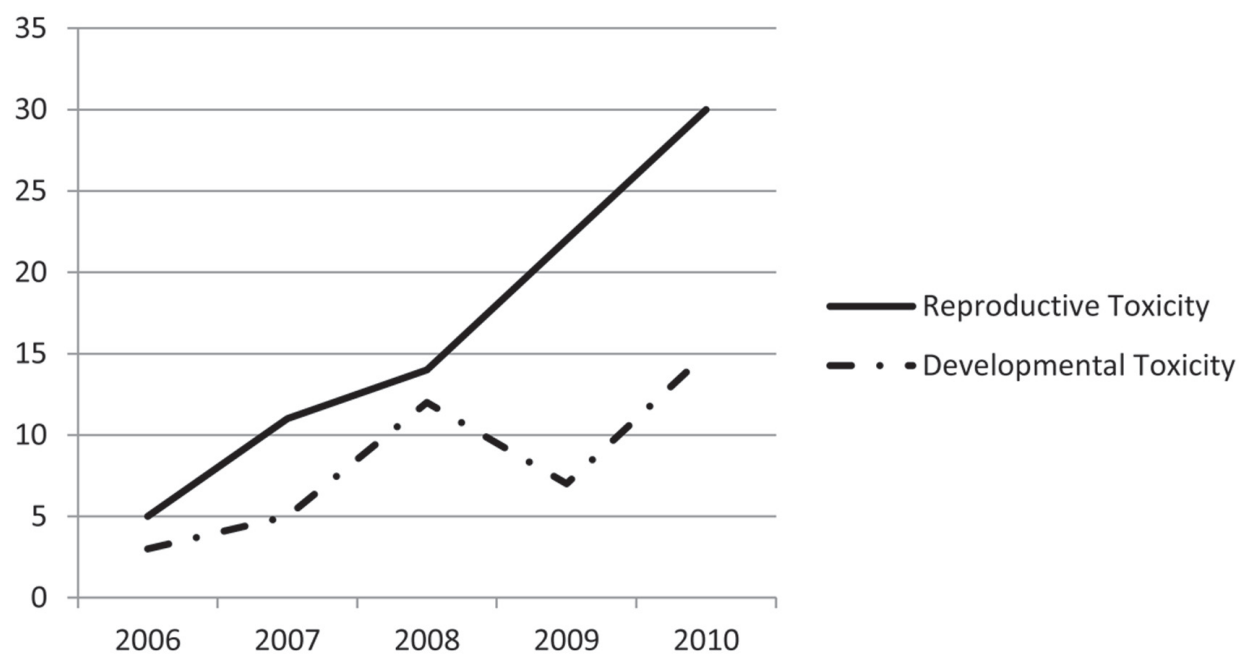

Fig. 2: Graphical representation of the number of in vivo tests performed later than 2006 used in the $400 \mathrm{REACH}$ dossiers analyzed

Tab. 11: Number of in vivo studies carried out between 2006 and 2010 used for registration in the 400 dossiers

\begin{tabular}{|c|c|c|c|c|c|c|}
\hline \multirow[b]{2}{*}{ Year } & \multicolumn{3}{|c|}{ Reproductive Toxicity } & \multicolumn{3}{|c|}{ Developmental Toxicity } \\
\hline & Total & OECD Test Method & \# of tests & Total & OECD Test Method & \# of tests \\
\hline \multirow[t]{4}{*}{2010} & \multirow[t]{4}{*}{30} & 416 & 2 & \multirow[t]{4}{*}{15} & 414 & 6 \\
\hline & & 421 & 6 & & 422 & 8 \\
\hline & & 422 & 21 & & 426 & 1 \\
\hline & & 413 & 1 & & & \\
\hline \multirow[t]{5}{*}{2009} & \multirow[t]{5}{*}{22} & 413 & 3 & \multirow[t]{5}{*}{7} & 414 & 4 \\
\hline & & 416 & 7 & & 422 & 3 \\
\hline & & 421 & 2 & & & \\
\hline & & 422 & 8 & & & \\
\hline & & Others & 2 & & & \\
\hline \multirow[t]{4}{*}{2008} & \multirow[t]{4}{*}{14} & 414 & 1 & \multirow[t]{4}{*}{12} & 414 & 4 \\
\hline & & 416 & 1 & & 416 & 1 \\
\hline & & 421 & 3 & & 422 & 3 \\
\hline & & 422 & 9 & & Others & 4 \\
\hline \multirow[t]{3}{*}{2007} & \multirow[t]{3}{*}{11} & 416 & 3 & \multirow[t]{3}{*}{5} & 414 & 2 \\
\hline & & 421 & 2 & & 422 & 2 \\
\hline & & 422 & 6 & & Others & 1 \\
\hline \multirow[t]{4}{*}{2006} & \multirow[t]{4}{*}{5} & 416 & 2 & \multirow[t]{4}{*}{3} & 414 & 1 \\
\hline & & 421 & 1 & & 422 & 1 \\
\hline & & 422 & 1 & & Others & 1 \\
\hline & & Others & 1 & & & \\
\hline
\end{tabular}


after 2006. Both numbers are clearly higher than the average performed in the years before, indicating that those studies where probably were performed to comply with REACH. Much more evident is the increase in the number of screening studies (OECD TG 421 and OECD TG 422): 47 studies were performed in the years 2008-2010. However, ECHA seems to be aware of those unauthorized tests and probably some actions will be taken (ECHA Report, 2011b).

This analysis provides input for further assessing the animal consumption for REACH purposes. Assuming that our set of 400 dossiers is representative of the whole array of dossiers submitted so far, Table 12 summarizes all tests that presumably were run after 2008, as listed in Table 11. Reproductive toxicity and developmental toxicity are considered together, as often one test method is inserted in both sections. In those cases, that method is counted once, and this is why the numbers of methods are different from those reported in Table 11. In only one case, the OECD TG 414 is proposed on two species (rat and rabbits), and this was counted twice. It should also be noted that the same study could be inserted twice and used as read-across several times. Additional missing information in our analysis concerns the number of dossiers that have been presented as groupings, which also could increase the numbers presented.

Table 12 lists the number of animals that are consumed, applying an average number of animals per test as previously evaluated (van der Jagt et al., 2004; Rovida and Hartung, 2009). Some methods are not focused on reproductive developmental toxicity and are given with a white background. Table 13 addresses costs using the average prices collected by Fleisher (2007) in a survey among the major testing facilities in the EU.

\subsection{Planned new studies}

REACH asks that all new studies, which are very demanding in terms of vertebrate animal use, include open public consultation

Tab. 12: Estimated number of animals used for the first registration deadline

\begin{tabular}{|c|c|c|c|c|c|}
\hline & $\begin{array}{l}\text { Average number } \\
\text { of animals }\end{array}$ & $\begin{array}{l}\text { Performed after } \\
2007 \text { in a set } \\
\text { of } 400 \text { dossiers }\end{array}$ & $\%$ & $\begin{array}{l}\text { Estimated to } \\
4,599 \text { dossiers }\end{array}$ & $\begin{array}{l}\text { Total number } \\
\text { of animals }\end{array}$ \\
\hline OECD TG 412 & 40 & 1 & $0.3 \%$ & 11 & 460 \\
\hline OECD TG 413 & 80 & 4 & $1.0 \%$ & 46 & 3,679 \\
\hline OECD TG 414 & 784 & 19 & $4.8 \%$ & 218 & 171,267 \\
\hline OECD TG 415 & 560 & 1 & $0.3 \%$ & 11 & 6,439 \\
\hline OECD TG 416 & 3200 & 10 & $2.5 \%$ & 115 & 367,920 \\
\hline OECD TG 421 & 560 & 14 & $3.5 \%$ & 161 & 90,140 \\
\hline OECD TG 422 & 412 & 44 & $11.0 \%$ & 506 & 208,427 \\
\hline OECD TG 426 & 1400 & 1 & $0.3 \%$ & 11 & 16,097 \\
\hline OECD TG 452 & 400 & 1 & $0.3 \%$ & 11 & 4,599 \\
\hline Total & & & & & 869,027 \\
\hline
\end{tabular}

Tab. 13: Estimated costs for new testing performed until the first registration deadline

\begin{tabular}{|c|c|c|c|c|c|}
\hline & $\begin{array}{l}\text { Average cost } \\
\text { per test }(€)\end{array}$ & $\begin{array}{l}\text { Performed after } \\
2007 \text { in a set } \\
\text { of } 400 \text { dossiers }\end{array}$ & $\%$ & $\begin{array}{l}\text { Estimated to } \\
\text { 4,599 dossiers }\end{array}$ & Total cost $(€)$ \\
\hline OECD TG 412 & 105,500 & 1 & $0.3 \%$ & 11 & $1,212,986$ \\
\hline OECD TG 413 & 250,000 & 4 & $1.0 \%$ & 46 & $11,497,500$ \\
\hline OECD TG 414 & 63,100 & 19 & $4.8 \%$ & 218 & $13,784,353$ \\
\hline OECD TG 415 & 54,600 & 1 & $0.3 \%$ & 11 & 627,764 \\
\hline OECD TG 416 & 328,000 & 10 & $2.5 \%$ & 115 & $37,711,800$ \\
\hline OECD TG 421 & 54,600 & 14 & $3.5 \%$ & 161 & $8,788,689$ \\
\hline OECD TG 422 & 92,000 & 44 & $11.0 \%$ & 506 & $46,541,880$ \\
\hline OECD TG 426 & $1,100,000$ & 1 & $0.3 \%$ & 11 & $12,647,250$ \\
\hline OECD TG 452 & 780,400 & 1 & $0.3 \%$ & 11 & $8,972,649$ \\
\hline Total & & & & & $141,784,871$ \\
\hline
\end{tabular}


for collecting all possible existing information, with the hope of fulfilling the data needs without performing the test. A section of the ECHA website ${ }^{7}$ lists all these consultations under the title "Proposals for tests involving vertebrate animals." As expected (Rovida and Hartung, 2009), the vast majority of planned studies concern reproductive and developmental toxicity. Of a total number of open consultations for 192 new substances (on 10 September, 2011), 93 suggest further assessment of reproductive toxicity and 120 of (pre)natal developmental, i.e. $48 \%$ and $62.5 \%$, respectively.

Planned studies in public consultation usually are published without specifying the guideline that is going to be applied ${ }^{8}$ (Tab. 14). The aim is to open the doors to as many opportunities as possible. Thus far, however, only four dossiers have reached the end of the process, with the authorization of all proposed tests, including reproductive toxicity and developmental toxicity. The hope that other dossiers will have a better outcome is not very high. Again, the opportunity for more advanced testing strategies with the application of in vitro methods was not considered.

Assuming that reproductive toxicity will require OECD TG 416 and (pre)natal developmental toxicity OECD TG 414, planned studies will use half a million animals or more (Tab.
15) and will cost more than $€ 60$ million (Table 16). These numbers are underestimated, as they are based only on open/ closed consultations, but also could be overestimated in some cases, when one study is used for more chemicals in readacross. In our assessment, we that $10.8 \%$ and $11.0 \%$ of submitted dossiers contain proposals for new tests on reproductive and developmental toxicity (Tab. 6). If those numbers are extrapolated to a total of 4,599 received dossiers, it leads to a total number of 497 new studies for reproductive toxicity and 506 new studies for developmental toxicity. Applying the same calculations to Table 15, this translates to a total of 396,704 animals for developmental toxicity and 1,590,400 animals for reproductive toxicity, i.e., a total of 1,978,104 animals for just these two endpoints and only for substances registered in the highest tonnage band.

These numbers are, on the one hand, somewhat overestimated if the same study can be used several times in grouping (another piece of information that, unfortunately, is not present in the public database) or in read-across. On the other hand, they are underestimated if ECHA decides to ask for a full test when only screening is proposed in a full dossier, when waiving or readacross is not accepted, and for those intermediates that do not fulfill the definition of being an intermediate.

\footnotetext{
7 http://echa.europa.eu/consultations/test_proposals/test_prop_cons_en.asp

8 http://echa.europa.eu/consultations/test_proposals/test_prop_cons_en.asp, accessed on September 10, 2011
}

Tab. 14: Public consultations on new testing proposals (latest update on September 10, 2011)

\begin{tabular}{|l|c|c|c|}
\cline { 2 - 4 } \multicolumn{1}{c|}{} & Total & Reproductive toxicity (two generation) & Prenatal/Developmental Toxicity \\
\hline Current Consultations & 90 & 40 & 74 \\
\hline Closed Consultations & 246 & 116 & 142 \\
\hline Completed Consultations & 5 & 3 & 3 \\
\hline Total & 341 & 159 & 219 \\
\hline
\end{tabular}

Tab. 15: Estimated number of animals that will be used to perform proposed tests on reproductive and developmental toxicity

\begin{tabular}{|l|c|c|c|}
\cline { 2 - 4 } \multicolumn{1}{c|}{} & No. of animals per test & No. of planned new tests & Total no. of animals \\
\hline OECD TG 414 & 784 & 219 & 171,696 \\
\hline OECD TG 416 & 3,200 & 159 & 508,800 \\
\hline Total & & & 680,496 \\
\hline
\end{tabular}

Tab. 16: Estimated costs to perform all proposed tests on reproductive and developmental toxicity

\begin{tabular}{|l|c|c|c|}
\cline { 2 - 4 } \multicolumn{1}{c|}{} & Cost per test $(€)$ & No. of planned new tests & Total cost $(€)$ \\
\hline OECD TG 414 & 63,100 & 219 & $13,818,900$ \\
\hline OECD TG 416 & 328,000 & 159 & $52,152,000$ \\
\hline Total & & & $65,970,900$ \\
\hline
\end{tabular}


A minor hope came from the last meeting of the Member State Committee at ECHA, where the request for a new twogeneration study for five substances could not find unanimous agreement. The application of OECD test guideline 443 for the extended one-generation reproductive toxicity study was proposed as an alternative (ECHA News Alert, 2011).

\subsection{In vitro opportunities}

The complete absence of in vitro approaches is difficult to accept, even though already predicted (Rovida, 2010). However, this is largely due to the ECHA guideline, which states that no in vitro method can be applied for REACH purposes in the fields of reproductive and developmental toxicity. The situation is even worse: the guideline describes in vitro methods as an opportunity to trigger further in vivo testing. The only real possibility for in vitro testing lies in justifying a read-across approach. Unfortunately, the considerable limitations of in vivo methods - with a predictivity known to be around $60 \%$ only (Hartung, 2009) - are not mentioned.

The only official website for alternative methods is the TSAR $^{9}$ (Tracking System for Alternative test methods Review, Validation and Approval in the Context of EU Regulations on Chemicals). In the area of reproductive toxicity, three methods are listed:

- EST: Embryonic Stem Cell Test for Embryotoxicity

- WET: Whole rat Embryo Embryotoxicity Test

- MM: Micromass Embryotoxicity Assay

The EST is proposed as a screening method, while WET and MM are discouraged as "Currently, its (their) general application would increase animal use." This attitude is also reflected in the recent report about alternative methods for cosmetic ingredient testing (Adler et al., 2011): "Only animal models are hitherto accepted as adequately representing the complexity and providing an assessment of the complex interaction of chemicals on the reproductive system." On the other hand, the European Commission recently funded the 5-year Integrated Project ReProTect to develop new in vitro tests to replace animal experimentation in reproductive toxicology ${ }^{10}$ with $€ 9.1$ million. The outcome from this project was very successful, with a proposal for a battery of tests that may replace in vivo methods in the near future (Schenk et al., 2010). Results from ReProTect are to be combined with other research projects ${ }^{11,12}$, demonstrating a lively and rapidly progressing arena. For example, preliminary experiments demonstrated that there were no false negative substance classifications in the feasibility study, making the ReProTect battery of tests suitable for screening or at least to confirm negative results from in vivo screening tests.

Therefore, even though full replacement is not available at the moment, some in vitro tests could complement the information derived from a screening test or confirm the result from an existing test that lacks information to be accepted as fully reliable but that could be accepted in a weight of evidence approach. REACH requires that the most advanced method must always be applied for the assessment of chemicals and it should be noted that the area of in vitro methods is developing fast.

It should be reminded that promotion of alternative methods is an explicit requirement of Article 1 of $\mathrm{REACH}$ and it is expected that ECHA invests much effort in this field. Article 117 of REACH requires that every five years the Commission publish a report about "the amount and distribution of funding made available by the Commission for the development and evaluation of alternative test methods." The first of the series is expected by June 1, 2012.

\subsection{Projection from the $\mathbf{4 0 0}$ analyzed dossiers to all 4,599 dossiers}

This sample of 400 dossiers allows us to project costs of the first phase of REACH. If all 4,599 dossiers were to lead to testing for reproductive and developmental toxicity, $€ 1.3$ billion and 13 million animals would be required. Reducing the number of intermediates (which do not require testing), the costs come down to $€ 0.9$ billion and 9.2 million animals. If all dossiers where submitters state "conclusive data lacking" (18\%) resulted in testing, $€ 234$ million and 1.3 million animals would be needed.

In contrast, submitters propose studies at costs of $€ 70$ million and almost 700,000 animals (Tab. 15, 16). It is worth noting that the number of studies already carried out after 2007 is even higher, i.e. costing $€ 140$ million and using almost 900,000 animals (Tab. 12, 13). Taken together, this first phase of REACH consumes about $€ 240$ million and uses almost 1.6 million animals for reproductive and developmental toxicity only (assumed to represent $90 \%$ of the total). However, it is likely that not all data will be accepted as submitted: Existing in vivo data will not always be acceptable, and whether waiving, read-across, and alternative techniques will be accepted by regulators, as suggested by industry, is not clear at all. A further increase in both numbers is likely.

\section{Comparison with previous estimation}

The number of substances for phase one of REACH is higher than expected $(3,599$ compared to the 2,700 originally expected by the European Commission). Numbers are not as high as our model calculation from 2009 (Rovida and Hartung, 2009) suggested, most likely because we do not have a linear spread of production volumes (especially for the high production volume (HPV) chemicals currently registered). Also, including several substances in one dossier might contribute to apparently lower numbers. As shown earlier (Hartung and Rovida, 2009b), all previous estimates were based on a single database from 19911994; we corrected for the increase from 12 to 27 member states,

\footnotetext{
9 http://tsar.jrc.ec.europa.eu

10 www.ReProTect.eu

11 www.esnats.eu

12 www.scrtox.eu
} 
plus others applying REACH and, on average, a 5\% increase in production volume per year.

The first surprise was that there is more existing data on developmental and reproductive toxicity available than expected (39.5\% and $42.3 \%$, respectively) instead of the $7 \%$ as estimated by the former European Chemicals Bureau, (Pedersen et al., 2003), but in line with earlier statements by industry. This is not what we see in the database of the US EPA for 2,000 HPV substances, where very little test information for reproductive toxicity is available (Bremer et al., 2007). Thus it appears that studies of lesser relevance have now been brought forward, but this cannot be confirmed at this stage. Furthermore, there is a clear indication that some studies were done just before registration, which is clearly illegal, as they would have required acceptance of the testing proposal after public consultation by ECHA. The extrapolation to all dossiers (Tab. 12,13) shows that we are talking about an impressive number of studies, which used about 900,000 animals and cost $€ 140$ million.

The very rigid guidance for testing is not followed by industry. Waiving is quite broadly applied (17.8\% for developmental and $13.3 \%$ for reproductive toxicity studies, plus $4.5 \%$ and $5 \%$, respectively, of voids), though the current guidance is extremely strict. Only $10.8 \%$ and $11 \%$ of dossiers proposed animal studies, while at least $47 \%$ of developmental and $18 \%$ of reproductive toxicity data are either lacking or inconclusive. This shows that roles are changing here: ECHA needs not to limit the testing, but to request it. This means that a pure completeness check of $5 \%$ of dossiers not suggesting tests will not suffice to attain the goals of REACH.

In vitro and in silico approaches play no role, an observation very much in line with our previous comments (Rovida, 2010). The limited use of (Q)SAR reflects the lack of predictive models as stated recently (Hewitt et al., 2010): "This study has shown that current modelling methods available for developmental toxicity are still in their infancy. Each approach considered in this study is limited by available toxicity data in the public arena and by mechanistic understanding." Some in vitro methodologies are available (Seiler and Spielmann, 2011; Marx-Stoelting et al., 2009; Schenk et al., 2010; West et al., 2010), but few are validated (Genschow et al., 2004) and none accepted for regulatory use or recommended in the guidance. REACH would, however, be open to their use on a weight of evidence basis. The fact that companies do not use this option reflects the general impression as to their limited acceptance (if at all for positive findings) and the possible triggering of even more extensive (animal) testing.

\section{Conclusions}

REACH is at a critical crossroads. The position the agency now takes toward the few test proposals received, the acceptability of existing data, waiving, and read-across will be very important. Revision of intermediates also deserves attention. As many animal tests as possible should be avoided, but they must be the right ones to avoid. Checking the completeness of only $5 \%$ of the large majority of dossiers - those that propose avoiding testing - will not work. This penalizes those who followed the guidance and suggested tests.

If only the proposed studies are done (about 219 developmental and 159 reproductive toxicity studies, when extrapolating to the entire number of dossiers, for phase one of REACH), the numbers will already exceed current European test capacities. Fleischer (2007) identified test capacities for 12 developmental studies in rabbits and 28 reproductive studies in rats per year in Europe (mainly used for pesticides and drugs). It is very unlikely that there is much more capacity and that all this could be handled in a few years. Test capacities cannot be easily created, as they require complex knowledge and experience (GLP, histopathology, etc.). This is the number used so far for chemical testing over the past 10 years. And this is only the first part of the program.

The use of alternatives so far is negligible. We need to use the momentum to foster alternative approaches, especially in reproductive toxicity testing. The first step forward would be the change from a two-generation to a one-generation study, which would reduce animal use and costs by more than $60 \%$. Unfortunately, although the OECD accepted this test, it has not yet been adopted for REACH (Gilbert, 2010). Another important opportunity would be the applicability of methods developed by ReProTect for confirming both positive and negative results. In our opinion, this would also dramatically enhance the knowledge about the chemicals' activity on human health, which is exactly in the spirit of REACH.

The purpose of REACH is to get much data on many chemicals. For the HPV chemicals, if only $11 \%$ of new tests are carried out, the information gained will be limited. But the feasibility of even this minimal program is questionable. At the same time, it is understandable that industry wants to avoid costly testing, especially since precautionary test methods will lead to many false allegations for toxic properties (Hartung, 2009). The dilemma can only be solved if it creates momentum for new approaches, but there is little indication that this is happening.

A legislative amendment of REACH is foreseen for 2012. We strongly advocate that the explicit requirements for OECD TG 414 and 416 disappear and applicability of (pre-)validated in vitro methods within the scope of Annex XI include the possibility of accepting both positive and negative results, if backed by satisfactory scientific evidence. It is worth remembering that none of the in vivo methods for testing reproductive and developmental toxicity has ever been validated.

Another important consideration concerns the strong differences between some registration dossiers: It seems unfair that diligent submitters admitted that their dossiers were lacking important information and asked for the permission to perform new tests, while others simply did the test without permissions or used data of limited scientific relevance to fill the box. At this point the better approach would be to halt the authorization for new in vivo tests and develop a more integrated strategy that takes advantage of in silico and in vitro approaches. This possibility may provide evidence to weigh whether the assessed substance is likely to be dangerous and requires extensive in 
vivo reproductive toxicity testing. In the meanwhile, a general control of all dossiers could take place. Only when this analysis is completed, a more modern approach can be implemented and used to fill the many gaps that are evident at this stage of the process.

\section{References}

Adler, S., Basketter, D., Creton, S., et al. (2011). Alternative (non-animal) methods for cosmetics testing: current status and future prospects - 2010. Arch. Toxicol. 85, 367-485.

Bremer, S., Pellizzer, C., Hoffmann, S., et al. (2007). The development of new concepts for assessing reproductive toxicity applicable to large scale toxicological programs. Curr. Pharm. Des. 13, 3047-3058.

CLP (2008). Regulations. Regulation (EC) No 1272/2008 of The European Parliament and of the Council of 16 December 2008 on classification, labelling and packaging of substances and mixtures, amending and repealing Directives 67/548/ EEC and 1999/45/EC, and amending Regulation (EC) No 1907/2006. Official Journal of the European Union L 353, $1-1355$.

Directive 67/548/EEC (1967). COUNCIL DIRECTIVE 67/548/ EEC of 27 June 1967 on the approximation of laws, regulations and administrative provisions relating to the classification, packaging and labelling of dangerous substances. Official Journal of the European Communities 196, 1-98.

ECHA (2008). Guidance on information requirements and chemical safety assessment Chapter R.7a: Endpoint specific guidance (428pp.). http://guidance.echa.europa.eu/ docs/guidance_document/information_requirements_r7a_ en.pdf?vers=20_08_08 (accessed 07.07.2011).

ECHA News Alert (2011). ECHA Refers a draft decision for one testing proposal to the Commission for the first time. ECHA/NA/11/45.

ECHA Press Release (2009). Clarification will avoid unnecessary animal tests, ECHA/PR/09/13. http://echa.europa.eu/ doc/press/pr_09_13_animal_testing_carification_20090915. pdf (accessed 11.07.2011).

ECHA REACH Fact Sheet (2009). Information requirements for repeated dose toxicity and reproductive toxicity - substances over 100 (and 1000) tones. ECHA-09-FS-05-EN. http://echa. europa.eu/doc/reach/reach_factsheet_testing.pdf (accessed 10.07.2011).

ECHA Report (2011a). Evaluation under REACH progress report 2010, ECHA-11-R-001-EN. http://echa.europa.eu/doc/ evaluation_under_reach_progress_report_2010_en.pdf (accessed 10.07.2011).

ECHA Report (2011b). The operation of REACH and CLP 2011, ECHA-11-R-003-EN. http://echa.europa.eu/publications/operation_reach_clp_2011_en.asp (accessed 10.07.2011).

ECHA Report (2011c). The use of alternatives to testing on animals for REACH regulation, ECHA-11-R-004-EN. http://echa.europa.eu/publications/alternatives_test_animals_2011_en.asp (accessed 10.07.2011).

Fleischer, M. (2007). Testing costs and testing capacity ac- cording to the REACH requirements - Results of a survey of independent and corporate GLP laboratories in the EU and Switzerland. J. Bus. Chem. 4, 96-114.

Genschow, E., Spielmann, H., Scholz, G., et al. (2004). Validation of the embryonic stem cell test in the international ECVAM validation study on three in vitro embryotoxicity tests. ATLA 32, 209-244.

Gilbert, N. (2010). Streamlined chemical tests rebuffed. Nature $463,142-143$.

Gilbert, N. (2011). Data gaps threaten chemical safety law. Nature 475, 150-151.

Hartung, T. (2009). Toxicology for the twenty-first century. Nature 460, 208-212.

Hartung, T. (2010). Food for thought ... on alternative methods for chemical safety testing. ALTEX 27, 3-14.

Hartung, T. and Rovida, C. (2009a). Chemical regulators have overreached. Nature 460, 1080-1081.

Hartung, T. and Rovida, C. (2009b). That which must not, cannot be... a reply to the ECHA and EDF responses to the REACH analysis of animal use and costs. ALTEX 26, 307-311.

Hewitt, M., Ellison, M. C., Enoch, S. J., et al. (2010). Integrating (Q)SAR models, expert systems and read-across approaches for the prediction of developmental toxicity. Reprod. Toxicol. 30, 147-160.

Höfer, T., Gerner, I., Gundert-Remy, U., et al. (2004). Animal testing and alternative approaches for the human health risk assessment under the proposed new European chemicals regulation. Arch. Toxicol. 78, 549-564.

IEH Report (2001). Testing requirements for proposals under the EC white paper "strategy for a future chemicals policy." Institute for Environment and Health. http://www.cranfield. ac.uk/health/researchareas/environmenthealth/ieh/ieh\%20 publications/w6.pdf (accessed 22.07.2009).

Klimisch, H. J., Andreae, M., and Tillmann, U. (1997). A systematic approach for evaluating the quality of experimental toxicological and ecotoxicological data. Regul. Toxicol. Pharmacol. 25, 1-5.

Marx-Stoelting, P., Adriaens, E., Ahr, H. J., et al. (2009). A review of the implementation of the Embryonic Stem Cell Test (EST). The report and recommendations of an ECVAM/ReProTect. ATLA 37, 313-328.

Pedersen, F., de Bruijn, J., Munn, S. and van Leeuwen, K. (2003). Assessment of additional testing needs under REACH - effects of (Q)SARs, risk based testing and voluntary industry initiatives. JRC Report EUR 20863.

REACH (2006). Regulation (EC) No 1907/2006 of the European Parliament and of the Council of 18 December 2006 concerning the Registration, Evaluation, Authorisation and Restriction of Chemicals (REACH), establishing a European Chemicals Agency, amending Directive 1999/45/EC and repealing Council Regulation (EEC) No 793/93 and Commission Regulation (EC) No 1488/94 as well as Council Directive 76/769/EEC and Commission Directives 91/155/EEC, 93/67/ EEC, 93/105/EC and 2000/21/EC. http://home.kpn.nl/reach/ downloads/reachtestingneedsfinal.pdf (accessed 05.11.2011). Official Journal of the European Union L 396, 1-849. 
Regulation 134/2009 (2009). Commission Regulation (EC) No 134/2009 of 16 February 2009 amending Regulation (EC) No 1907/2006 of the European Parliament and of the Council on the Registration, Evaluation, Authorisation and Restriction of Chemicals (REACH) as regards Annex XI. Official Journal of the European Union L 46, 3-5.

Regulation 340/2008 (2008). Commission Regulation (EC) No 340/2008of 16 April 2008on the fees and charges payable to the European Chemicals Agency pursuant to Regulation (EC) No1907/2006 of the European Parliament and of the Council on the Registration, Evaluation, Authorisation and Restriction of Chemicals (REACH). Official Journal of the European Union L 107, 6-26.

Regulation 440/2008 (2008). Council Regulation (EC) No 440/2008of 30 May 2008 laying down test methods pursuant to Regulation (EC) No 1907/2006 of the European Parliament and of the Council on the Registration, Evaluation, Authorisation and Restriction of Chemicals (REACH). Official Journal of the European Union L 142, 1-739.

Rovida, C. and Hartung, T. (2009). Re-evaluation of animal numbers and costs for in vivo tests to accomplish REACH legislation requirements for chemicals - a report by the transatlantic think tank for toxicology $\left(\mathrm{t}^{4}\right)$. ALTEX 26, 187-208.

Rovida, C. (2010). Food for thought ... why no new in vitro tests will be done for REACH by registrants. ALTEX 27, 175183.

RPA and Statistics Sweden (2002). Assessment of the impact of new regulations in the chemicals sector. Final Report prepared for European Commission, DG ENTR. http://ec.europa.eu/ enterprise/reach/docs/whitepaper/bia_report-2002_06_en.pdf (accessed 05.09.2011)

Schenk, B., Weimer, M., Bremer, S., et al. (2010). The ReProTect Feasibility Study, a novel comprehensive in vitro approach to detect reproductive toxicants. Reproductive Toxicology 30, 200-218.
Seiler, A. and Spielmann, H. (2011). The validated embryonic stem cell test to predict embryotoxicity in vitro. Nat. Protoc. 6, 961-978.

van der Jagt, K., Munn, S.,Tørsløv,J., and de Bruijn, J. (2004). Alternative approaches can reduce the use of test animals under REACH. Addendum to the report: Assessment of additional testing needs under REACH Effects of (Q)SARS, risk based testing and voluntary industry initiatives. JRC Report EUR 21405 EN. http://publications.jrc.ec.europa.eu/repository/bitstream/111111111/8790/1/EUR\%2021405\%20EN. pdf (accessed 27.07.2011).

West, P. R., Weir, A. M., Smith, A. M., et al. (2010). Predicting human developmental toxicity of pharmaceuticals using human embryonic stem cells and metabolomics. Toxicol. Appl. Pharmacol. 247, 18-27.

\section{Acknowledgements}

The most valuable discussions and contributions by Dr Thomas Hartung, Baltimore, to this paper are gratefully appreciated. An interim analysis based on the first 200 dossiers of this study was reported by Dr. Natasha Gilbert (2011); the valuable discussions with her shaped this analysis.

\section{Correspondence to}

Costanza Rovida

CAAT-Europe at the University of Konstanz

Universitaetsstr. 10

78464 Konstanz

Germany

e-mail: costanza.rovida@chimici.it 